\title{
Expanding crossover research: The crossover of job-related self-efficacy within couples
}

\section{Angela Neff}

Department of Psychology, University of Konstanz, Germany

\section{Cornelia Niessen}

Institute of Psychology, Friedrich-Alexander University of Erlangen-Nürnberg, Erlangen, Germany

\section{Sabine Sonnentag}

Department of Psychology, School of Social Sciences, University of Mannheim, Germany

\section{Dana Unger}

Department of Psychology, School of Social Sciences, University of Mannheim, Germany

\begin{abstract}
This article reports a study that examined the crossover of job-related self-efficacy within working couples, its underlying mechanisms, and its work-related consequences. We proposed that the job-related self-efficacy of one partner (the 'actor') can be transmitted to the other partner (the 'partner'). By building on self-efficacy research (Bandura, 1997), we hypothesized vicarious experience and verbal persuasion to be the mediators underlying this crossover process. We expected that the crossover of job-related self-efficacy would in turn result in the partner's altered engagement at work. Using a sample of 102 professionals with an academic degree and their working partners, we conducted multilevel analyses using the actor-partner interdependence model. Our analyses offered support for our hypotheses. The actor's job-related selfefficacy related positively to the partner's job-related self-efficacy. This relation was mediated by the partner's perceived vicarious experience and verbal persuasion.
\end{abstract}

\section{Corresponding author:}

Angela Neff, Department of Psychology, Work and Organizational Psychology, University of Konstanz, Box 4278457 Konstanz, Germany.

Email: angela.neff@uni-konstanz.de 
Additionally, the actor's job-related self-efficacy indirectly related to the partner's work engagement through the partner's job-related self-efficacy.

\section{Keywords}

actor-partner interdependence model, crossover, job-related self-efficacy, verbal persuasion, vicarious experience

Self-efficacy generally is defined as the 'beliefs in one's capabilities to organize and execute the courses of action required to produce given attainments' (Bandura, 1997: 3). Applied to the work-context, job-related self-efficacy predicts multiple positive workrelated outcomes (Abele and Spurk, 2009; Stajkovic and Luthans, 1998). Therefore, one major aim of research has been to find predictors of employees' job-related self-efficacy (Eden and Kinnar, 1991). Until now, research hereby has very much focused on workrelated antecedents of job-related self-efficacy (e.g. Eden et al., 2000; McNatt and Judge, 2008). Although research on work-related sources of job-related self-efficacy has led to important results, these studies nevertheless demonstrate that a large proportion of the variance in job-related self-efficacy remains unexplained when taking only work-related antecedents into account (e.g. McNatt and Judge, 2004). Therefore, other factors in people's lives may contribute to the prediction of job-related self-efficacy.

Recent research increasingly focuses on the interplay between a person's work and family life (Eby et al., 2005; Voydanoff, 2002) and emphasizes that experiences made at home should not leave a person's work life unaffected (and vice versa). Especially with the increasing number of dual-earner couples in Western societies (Ilies et al., 2007), both partners share similar roles and thus the boundaries between a person's work and family life become more and more blurred. For example, a study by Bakker et al. (2008) demonstrates quite vividly that a person's work-related experiences do not stay in the work context but can be carried into the other partner's working life through spillover and crossover processes. We propose that such a crossover process can also occur for job-related self-efficacy. When both partners pursue a career, talk about their jobs while at home and thereby witness how the other partner copes with difficult situations at work - albeit the specific jobs might be different - self-efficacy should not remain unaffected. For example, if one partner sees him- or herself confronted with obstacles at work such as an extremely high workload, this person's partner who also works can give advice based on his or her own experiences and the partner can learn from his or her way to handle these kinds of problems. Based on these considerations, our study sheds light on antecedents of job-related self-efficacy that are generated through the interaction with one's partner. Specifically, our study examines how one partner's job-related self-efficacy might affect the other partner.

According to crossover research (Westman, 2001), work-related psychological states can be transmitted between partners in relationships. Although crossover effects have been shown for a number of work-related states and experiences (Bakker, 2005; Demerouti et al., 2005; Song et al., 2008), until now no study has examined the possible transmission of job-related self-efficacy between partners. Because of the interplay between a person's working and private life (Eby et al., 2005; Voydanoff, 2002), we 
propose that in dual-earner relationships a person's partner can be an additional source of this person's job-related self-efficacy. We therefore investigate the crossover of jobrelated self-efficacy, the mechanisms linking both partners' job-related self-efficacy beliefs, as well as the work-related consequences of the crossover process.

We build on self-efficacy research (Bandura, 1997) and argue that the job-related self-efficacy beliefs of one partner (the 'actor') can be transmitted to the other partner (the 'partner') through vicarious experience and verbal persuasion. Furthermore, we postulate that this crossover of job-related self-efficacy will in turn become apparent in the partner's work context. Self-efficacy is a central personal self-evaluation that predicts personal motivation (Bandura, 1997). As mentioned earlier, concerning the work context, positive effects of job-related self-efficacy on positive work-related outcomes are well documented (Stajkovic and Luthans, 1998). In our study, we focus on work engagement as a positive affective-motivational outcome and propose that the crossover of job-related self-efficacy will be in turn related to the partner's work engagement (see Figure 1).

Thus, the aim of our study is threefold. First, we test the possible crossover of jobrelated self-efficacy. We posit that in dual-earner relationships a person's partner can influence this person's job-related self-efficacy. We therefore assume that a person brings home his or her job-related self-efficacy beliefs, thereby affecting his or her partner via crossover processes. Second, we examine mechanisms linking both partners' job-related self-efficacy beliefs. We hereby postulate that vicarious experience and verbal persuasion mediate the crossover of job-related self-efficacy. These mediators are derived from research on general self-efficacy (Bandura, 1997) and have already been shown to affect peoples' selfefficacy beliefs in the work context (Eden and Kinnar, 1991; Mellor et al., 2006). In a final step, we address work-related consequences of the crossover process. We argue that through the crossover of job-related self-efficacy a person's work engagement can be affected. This assumption is based on the central role of self-efficacy expectations for personal motivation (Bandura, 1997). In the work context, self-efficacy has already been found to be positively related to a person's work engagement (Xanthopoulou et al., 2009a).

Our study thereby aims to contribute to existing research in two ways. First, as mentioned earlier, job-related self-efficacy is an important antecedent of multiple positive work-related outcomes (Abele and Spurk, 2009; Stajkovic and Luthans, 1998). Therefore, it is crucial to understand how employees' job-related self-efficacy beliefs are formed. We believe that through the close interdependence between a person's work and family life (Eby et al., 2005; Voydanoff, 2002) self-efficacy can also be formed outside a person's work life. By investigating the role of one's working partner for a person's jobrelated self-efficacy we want to contribute to existing literature on the sources of job-related self-efficacy and want to detect antecedents of these self-efficacy beliefs that go beyond the direct work context.

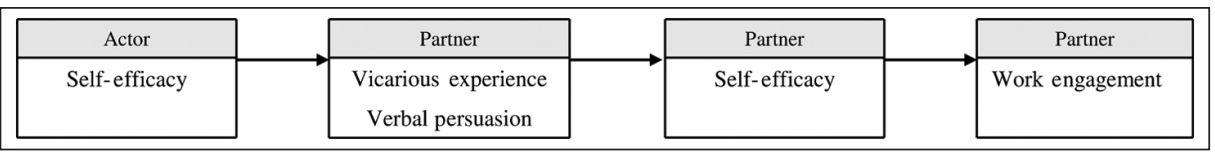

Figure I. Model proposed in our study. 
Second, by investigating the crossover of job-related self-efficacy within working couples we aim to extend the existing literature on crossover processes (Westman, 2001). Until now, most crossover research has focused on the transmission of negative psychological states such as stress or strain (Bakker et al., 2009). Following the perspective that a person's work and private life can also be mutually enriching (Greenhaus and Powell, 2006), we want to contribute to research on positive crossover processes by investigating the crossover of a central positive work-related self-evaluation - people's job-related self-efficacy.

\section{The crossover process}

To explain the transmission of job-related self-efficacy we build on crossover research. According to Westman (2001), crossover can be defined as a dyadic inter-individual transmission of psychological states between two partners. It has been shown that a person's positive and negative psychological states, such as stress, mood, and engagement can be transmitted to his or her partner (Demerouti et al., 2005; Song et al., 2008). Westman (2001) defined three mechanisms for the crossover process. First, crossover can be an empathic reaction. This means that a person can catch the psychological states of his or her partner and thereby can be affected. This empathic reaction process mostly seems to account for affective states such as mood or emotions, similarly to the phenomenon of mood contagion (Neumann and Strack, 2000; Song et al., 2010). As job-related self-efficacy is a cognitive-motivational construct, we do not assume an affective contagion of job-related self-efficacy via an empathic reaction. The second mechanism refers to the spuriousness of crossover effects. This means that in some cases psychological states are only seemingly transmitted between two partners and are actually the result of a couple's similar environment or background. To rule out this spurious relation we conducted some additional analyses which we will explain in detail at the end of this section. The third mechanism (Westman, 2001) describes crossover as an indirect process and thus postulates mediators underlying the crossover process. We focus on the last mechanism and assume the crossover of job-related self-efficacy to be an indirect process. We derive the mediators linking both partners' job-related self-efficacy perceptions - vicarious experience and verbal persuasion - from research on general self-efficacy (Bandura, 1997).

\section{Self-efficacy research}

Self-efficacy beliefs are a central predictor of personal behavior because they determine 'how much effort people will expend and how long they will persist in the face of obstacles and aversive experiences' (Bandura, 1977a: 194). Self-efficacy is a multi-faceted, domain-specific construct. Thus, a person can have different levels of self-efficacy depending on the domain in question (Bandura, 1997). This implies that in order to make valid predictions of a person's behavior in a given domain one should assess the person's self-efficacy in this corresponding field. In our study, we therefore focus on job-related self-efficacy as an employee's 'beliefs in one's capabilities to organize and execute the courses of action required to produce given attainments' (Bandura, 1997: 3) at work. 
Job-related self-efficacy has been shown repeatedly to be an important predictor of employees' positive job-related behavior (Abele and Spurk, 2009; Stajkovic and Luthans, 1998). But how do individuals develop their beliefs about their self-efficacy in a given domain? According to Bandura's (1977b) social learning theory, one major source of behavioral learning stems from observation of and interaction with others. This means that learning does not only have to result from experiences made by oneself. In line with this proposition, Bandura (1997) suggests that self-efficacy in a given domain can rather have four different sources: performance accomplishments (i.e. the personal encounter of success and the overcoming of difficulties); emotional arousal (i.e. physiological states like aversive arousal that can cause doubts in one's own capability); vicarious experience (i.e. modeling through the observation of other people); and verbal persuasion (i.e. verbal encouragement by other people). The first two sources of self-efficacy refer to an individual's personal experiences and are not directly dependent on the social context. Vicarious experience and verbal persuasion, however, both directly involve a person's social environment and also have been shown to positively affect self-efficacy in the work context (Eden and Kinnar, 1991; Mellor et al., 2006; Prussia and Kinicki, 1996). We posit that when considering a person's social environment, one's partner is an important part. We therefore assume vicarious experience and verbal persuasion to be crucial in the crossover of job-related self-efficacy between partners in dual-earner relationships.

First, vicarious experience means that belief in one's capabilities can be acquired by the observation of relevant others. Thus, other people can act as models for one's own self-expectations. Observing other people being convinced of their capabilities and being successful in a given domain can foster the expectation that oneself can be equally successful. But with whom do people compare themselves? We postulate that besides a person's co-workers, this person's working partner can be an additional point of reference for his or her job-related competencies. This notion is supported by research on social comparisons in relationships (Pinkus et al., 2008). Pinkus et al. (2008) found that couples compare themselves with respect to their skills and abilities on a daily basis. Therefore, we believe that people are aware of their partner's job-related behavior in the face of difficulties and the conviction in their job-related capabilities and that this perception models their own job-related self-efficacy. More precisely, we hypothesize that the actor's job-related self-efficacy affects the partner's job-related self-efficacy through vicarious experience.

Second, significant others can also affect a person's job-related self-efficacy beliefs via verbal persuasion, i.e. by expressing their trust in this person's capabilities. For many people, their own partner is an important confidant and a major source of social support when it comes to their job-related problems (Aryee et al., 1999; Seiger and Wiese, 2009). We therefore postulate that a person's job-related self-efficacy can be increased via the verbal persuasion of this person's partner. According to Bandura (1997), verbal persuasion has a stronger impact if the 'receiving' person assumes that the person who tries to persuade is successful him- or herself in the given domain. Thus, although both people high and low in job-related self-efficacy most probably try to encourage their partners through verbal persuasion, we assume that verbal persuasion given by a person who himor herself is high in job-related self-efficacy will be more persuasive and thus more 
effective in the persuasion process. Therefore, partners with spouses high in job-related self-efficacy should take their verbal persuasion more seriously as the 'source' of this verbal persuasion has a higher credibility which, in turn, should increase the partner's job-related self-efficacy.

Specifically, we hypothesize that the actor's perceived job-related self-efficacy crosses over to the partner via the verbal persuasion experienced by the partner.

Hypothesis 1: There is a crossover between the actor's and the partner's job-related self-efficacy.

Hypothesis 2: The crossover of job-related self-efficacy is mediated by the partner's perceived vicarious experience (Hypothesis $2 \mathrm{a}$ ) and verbal persuasion (Hypothesis $2 \mathrm{~b}$ ).

\section{Work-related consequences of the crossover of job- related self-efficacy}

In a further step, we examined the work-related consequences of the crossover of jobrelated self-efficacy. Is the transmission of job-related self-efficacy between the actor and the partner related to the partner's working behavior? As mentioned earlier, a person's job-related self-efficacy beliefs are a central determinant in the work context. Positive effects of self-efficacy on performance-related outcomes are well documented (Abele and Spurk, 2009; Stajkovic and Luthans, 1998). An important indicator for multiple performance-related outcomes is work engagement, as it has been shown to predict financial returns, loyalty, and performance ratings (Bakker and Bal, 2010; Bakker et al., 2004; Salanova et al., 2005; Xanthopoulou et al., 2009b). Work engagement is defined as 'a positive, fulfilling, work-related state of mind that is characterized by vigor, dedication, and absorption' (Schaufeli and Bakker, 2004: 295). Furthermore, job-related selfefficacy has already been found to be related positively to work engagement (Xanthopoulou et al., 2008; Xanthopoulou et al., 2009a). Thus, we believe that the transmission of job-related self-efficacy between the actor and the partner should in turn result in the partner's higher work engagement. Specifically, we hypothesize an indirect effect of the actor's job-related self-efficacy on the partner's work engagement through the partner's job-related self-efficacy.

Hypothesis 3: The actor's job-related self-efficacy indirectly predicts the partner's work engagement through the partner's job-related self-efficacy.

\section{Alternative explanations}

According to Westman (2001), crossover effects can be spurious in the sense that there is no genuine transmission of psychological states between partners. Instead, there can be similar levels of the construct in question owing to factors such as a similar environment shared by both partners (e.g. Song et al., 2010). In our study, we focused on another alternative explanation for a crossover of job-related self-efficacy. One obvious alternative explanation for the transmission of job-related self-efficacy could be that both partners already shared a similar level of job-related self-efficacy when they met for the first time. Research on 'assortative mating' suggests that people tend to choose partners right 
from the beginning who are similar to themselves in various aspects, such as personality, emotions and behavior (Gonzaga et al., 2007; Tambs and Moum, 1992). One explanation for this phenomenon is that people are initially attracted to similar others (Gonzaga et al., 2007). However, up to now, the 'assortative mating' perspective, to our knowledge, has not been investigated with respect to people's self-efficacy. To rule out this alternative explanation we conducted additional analyses testing two indicators of the couples' initial similarity (similarity of educational background and retrospective general similarity) as possible moderators in the crossover process. Hereby, the basic idea was to test if the strength of the relation between both partners' job-related self-efficacy was influenced by the degree of both partners' initial similarity. If assortative mating hereby should cause the positive association between both partners' job-related self-efficacy, these moderation analyses should reveal that the supposed crossover effect only holds for initially very similar partners.

\section{Method}

\section{Procedure and sample}

Our sample was obtained from a German online panel provider (respondi AG; see also Selenko et al., 2011). Participation in this online panel is open to everybody interested and is not directly financially rewarded. However, by participating in online studies, panel members can collect bonus points that can be exchanged later in gift vouchers and other rewards. To recruit participants, the online panel provider first contacted panel members who lived in a heterosexual relationship, had an academic degree, and held a full-time job. All of those contacted participants then filled in a screening survey in which they reported whether their partner was also working with at least 20 hours average working time per week and whether both partners shared a common household. If this was the case, the contacted participant was asked if he or she would agree to give the panel provider his or her partner's email address so that the partner could be contacted separately. If the participant was willing to give the email address he or she was passed to the actual online questionnaire. Afterwards, the online panel provider contacted the panel members' partners separately via email and referred them to the same questionnaire as the online panel members. To be included in the final dataset, both partners had to fill in their questionnaire completely.

Following this procedure, we obtained a final sample of 102 couples (204 participants). To rule out selective drop-out, we compared this final sample of 204 participants with those participants who had filled in their own questionnaire completely but whose partners had not provided a complete dataset $(N=213$ participants). The two groups did not differ significantly with respect to the core study variables job-related self-efficacy $(t(415)=-.997, n s)$, work engagement $(t(415)=.112, n s)$, vicarious experience $(t(415)$ $=-1.257, \mathrm{~ns})$, and verbal persuasion $(t(415)=-.694, \mathrm{~ns})$.

Concerning core demographic variables, the average length of the couples' relationship was 11.66 years $(\mathrm{SD}=6.25)$, with 63.7 per cent being married and 51.0 per cent having children $(M=2.66, \mathrm{SD}=.64)$. Participants' average age was 37.75 years $(\mathrm{SD}=$ 7.58). As intended, the vast majority of our sample was fairly well educated, with 78.0 per cent having finished university or technical college and 37.3 per cent having a leadership 
position. Most of our participants $(67.6 \%)$ were employees in private organizations. Concerning the average working time, participants' average contractual working hours were 30.83 hours per week $(\mathrm{SD}=14.59)$. However, the actual working time was 41.17 hours per week on average $(\mathrm{SD}=9.86)$.

\section{Measures}

We collected our data with an online questionnaire that was distributed independently to each partner. All items were in German.

We assessed job-related self-efficacy with the eight items from the general self-efficacy scale from Chen et al. (2001). As we wanted to assess job-related self-efficacy, we adapted the items to tap self-efficacy with reference to one's job (e.g. 'When facing difficult tasks at work, I am certain that I will accomplish them'). The items were rated on a five-point Likert scale ranging from (1) 'totally disagree' to (5) 'totally agree'.

We measured vicarious experience with a modified version of the vicarious learning subscale derived from the sources of self-efficacy scale by Lent et al. (1991). We adapted the items to measure vicarious learning from one's partner concerning job-related selfefficacy. The adapted scale finally consisted of eight items (see Appendix for exact wording of all items $)$ and was again rated on a five-point Likert scale ( 1 = 'totally disagree'; $5=$ 'totally agree').

We measured verbal persuasion with a modified subscale of Lent et al.'s (1991) sources of self-efficacy scale. This time, we adapted eight items to assess the degree of perceived verbal persuasion by the partner regarding one's job-related self-efficacy (see Appendix for exact wording of all items). Again, all items were answered on a five-point Likert scale ( 1 = 'totally disagree'; 5 = 'totally agree').

We measured work engagement with the nine items of the short version of the Utrecht Work Engagement Scale (Schaufeli et al., 2006; e.g. 'At my work, I feel bursting with energy').

\section{Construct validity}

To ensure that job-related self-efficacy, vicarious experience, verbal persuasion, and work engagement constitute distinct constructs, we conducted multilevel confirmatory factor analyses (CFAs) with Mplus, taking into account the person - as well as the couple level of our data set. Results from the CFAs revealed a better fit of the assumed fourfactor model $\left(\chi^{2}=684.719\right.$, d.f. $=489, \chi^{2} /$ d.f. $\left.=1.400, \mathrm{RMSEA}=.044, \mathrm{CFI}=.950\right)$ than the best fitting three-factor model (Satorra-Bentler scaled (S-B) $\Delta \chi^{2}=123.160$, $\Delta$ d.f. $=3$, $p<.001$ ), the best fitting two-factor model (Satorra-Bentler scaled (S-B) $\Delta \chi^{2}=439.734$, $\Delta$ d.f. $=5, p<.001$ ), and the one-factor model (Satorra-Bentler scaled (S-B) $\Delta \chi^{2}=$ 614.687, $\Delta$ d.f. $=6, p<.001)$.

\section{Control variables}

Person-level control variables. Concerning the relation between age and self-efficacy, Bandura (1997: 196) states that self-efficacy beliefs in 'the major areas of functioning' tend to stabilize in middle age. This could result in older participants being less easily affected by 
their partners. Additionally, some studies indicate that the relation between job-related self-efficacy and other constructs also seems to depend on the participants' gender (Schmitt, 2008; Wang et al., 2010). Thus, men and women could be unequally affected by their partners' self-efficacy. We therefore controlled for age and gender $(1=$ female; $2=$ male) in our analyses. Furthermore, the average time spent with the partner is imperative to control. The more time both partners spend together, the more likely vicarious experience and verbal persuasion are to happen. Thus, we also controlled for the average length of interaction with the partner during the week (in hours).

Couple-level control variables. We assumed that the longer the couples had been together already the more likely it would be that self-efficacy crossover had occurred. Thus, we controlled for the length of the couples' relationships (in years). Furthermore, having children can be associated with an increased perceived conflict between family and work, which in turn can decrease a person's job-related self-efficacy (Wang et al., 2010). Thus, we also controlled for whether or not the couple had children $(0=$ no children; $1=$ children).

\section{Variables used in additional analyses}

On the person level we measured how the partner rated his or her general similarity to his or her partner at the time they met for the first time. We hereby instructed participants to think back to the time they had met their partners for the first time and assess their similarity at that time with two self-constructed items on a five-point Likert scale ranging from (1) 'not at all' to (5) 'extremely' ('When you and your partner met: How similar were you with respect to ... (1) ... your success at work; (2) ... your conviction in your capabilities').

On the couple level we assessed the similarity of both partners with respect to their education. We had asked both partners separately if they had finished a university or technical college. From the answers we generated a dichotomous educational similarity index $(0=$ low educational similarity; $1=$ high educational similarity $)$.

\section{Data analysis}

Partners within relationships share a lot of common external influences and affect each other through their regular interaction. Thus, when analyzing the transmission of psychological states within couples one has to take into account this common variance shared by the couples. Technically speaking, our data were structured hierarchically, with persons being nested within couples (Bryk and Raudenbush, 1992). We therefore applied hierarchical linear modeling to analyze our data, using the actor-partner interdependence model (APIM; Kenny et al., 2006). In line with earlier APIM-studies (e.g. Knabb et al., 2012), we included each person within the couple both as the 'actor' and as the 'partner' into analyses. This way the APIM allows analysis of intra-individual effects (so-called 'actor effects') as well as inter-individual effects (so-called 'partner effects') within a couple. 'Partner effects' describe the reciprocal relation between the partners, i.e. in our sample the crossover of job-related self-efficacy between men and women as well as between women and men. For these analyses we used the HLM 6 software package 
(Raudenbush et al., 2004). We centered all person-level as well as couple-level predictor and control variables at the grand mean.

\section{Results}

Table 1 shows means, standard deviations, zero-order correlations, and Cronbach alphas for all study variables.

\section{Preliminary analyses}

In a first step, we calculated the amount of variability between persons and couples for all of our predictor, mediator, and outcome variables to affirm hierarchical linear modeling to be the appropriate analysis procedure. Thus, we computed the intra-class correlations for job-related self-efficacy, vicarious experience, verbal persuasion, and work engagement based on the two-level intercept-only models (null models) of the respective variable. For job-related self-efficacy, 75 per cent of the variance was attributable to between-person variations, whereas 25 per cent of the variance was attributable to between-couple variations (see null model in Table 2). For vicarious experience, the variance component on the person level was .21 $(\mathrm{SE}=.03)$ and the variance component on the couple level was $.08(\mathrm{SE}=.03)$. Therefore, 72 per cent of the variance of vicarious experience was attributable to the person level and 28 per cent of the variance was attributable to between-couple variations. For verbal persuasion, the variance component on the person level was $.24(\mathrm{SE}=.03)$ and the variance component on the couple level was $.19(\mathrm{SE}=.05)$. Thus, 55 per cent of the variance of verbal persuasion was attributable to variation between persons and 45 per cent of variance was attributable to the couple level. Finally, for work engagement, 56 per cent of variance was attributable to betweenperson variations whereas 44 per cent of variance was attributable to between-couple variations (see null model in Table 3). To sum up, a substantial proportion of variance was explained on the couple level with variations ranging from 25 per cent to 45 per cent, emphasizing the importance of taking into account the couple level in our analyses.

\section{Test of hypotheses}

The crossover of job-related self-efficacy (Hypothesis I). To test Hypothesis 1, we compared three nested models: the null model, Model 1, and Model 2. In the null model, the intercept was included as the only predictor. In Model 1, all control variables at the person level (i.e. partner's age, gender, and the couple's average length of interaction during the week - rated by the partner) and couple level (i.e. the couple's length of relationship [in years] and whether the couple had children or not) were added. In the final model (Model 2), we included the actor's self-efficacy as the core predictor variable. We compared the model fit of these nested models by calculating the difference between a model's likelihood ratio and the previous model's likelihood ratio. This difference follows a chi-square distribution, and the degrees of freedom correspond to the number of variables added in each model. Results are depicted in Table 2. Model 1 (including the control variables) showed a significantly better model fit 


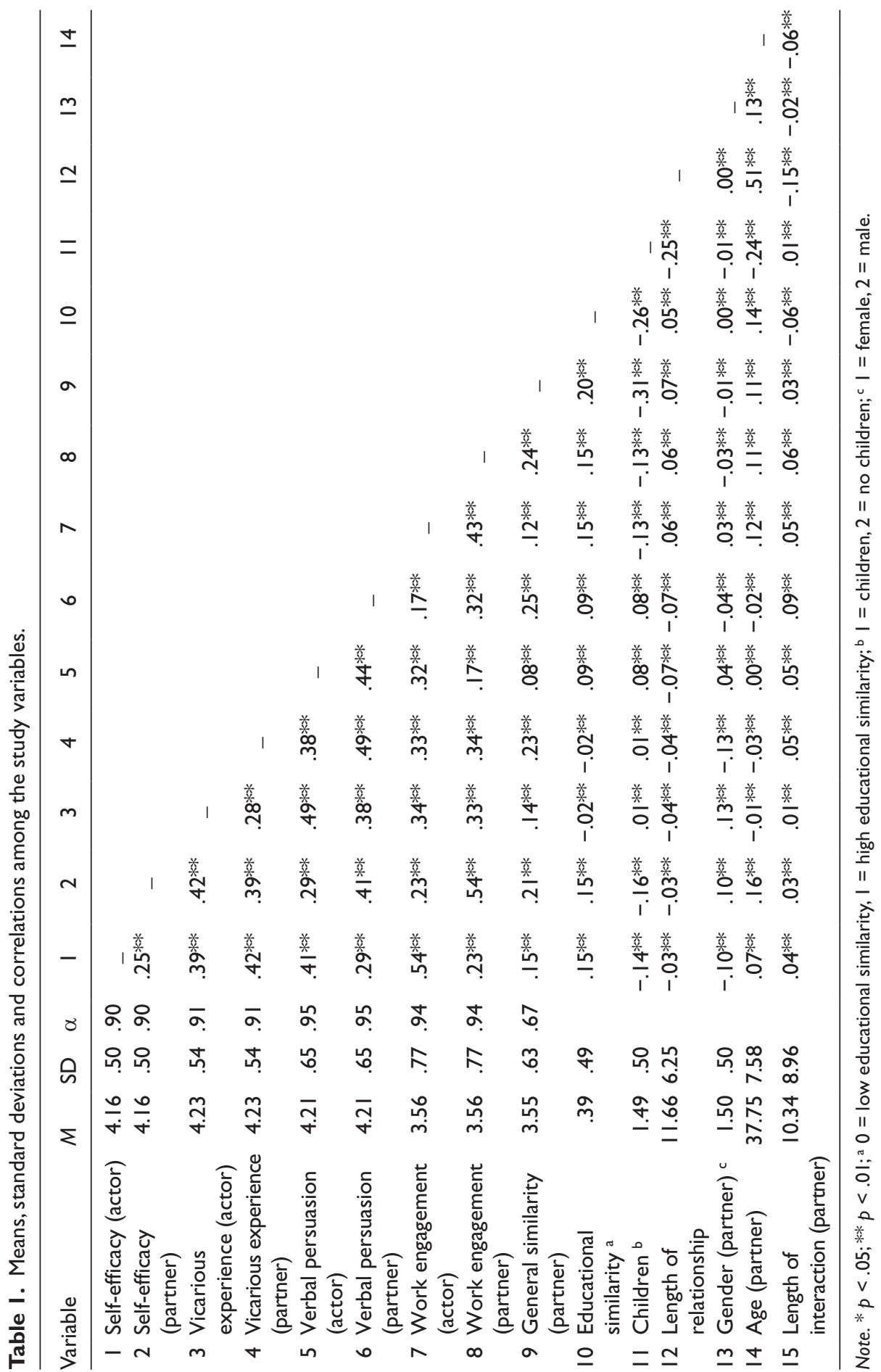




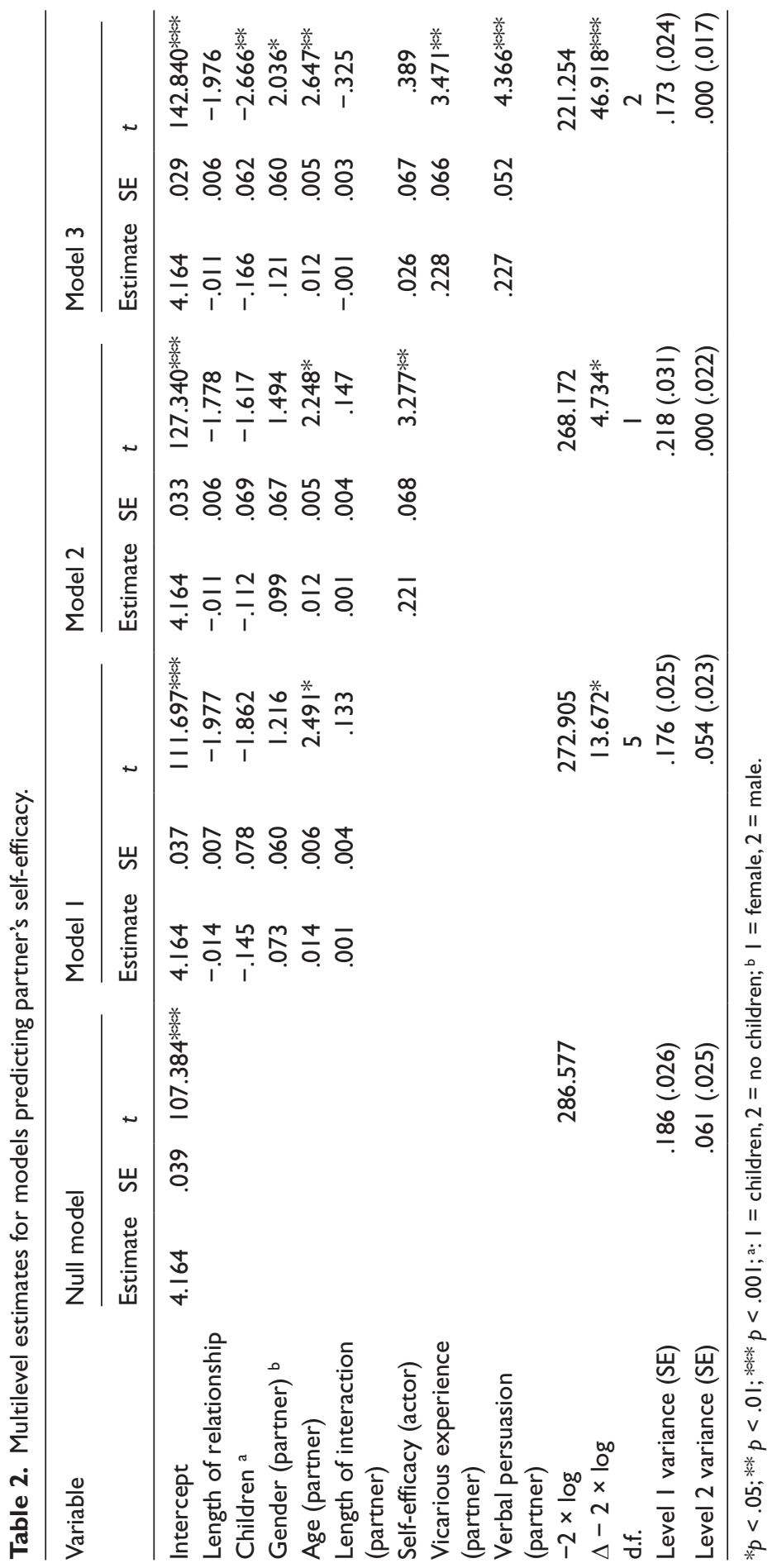




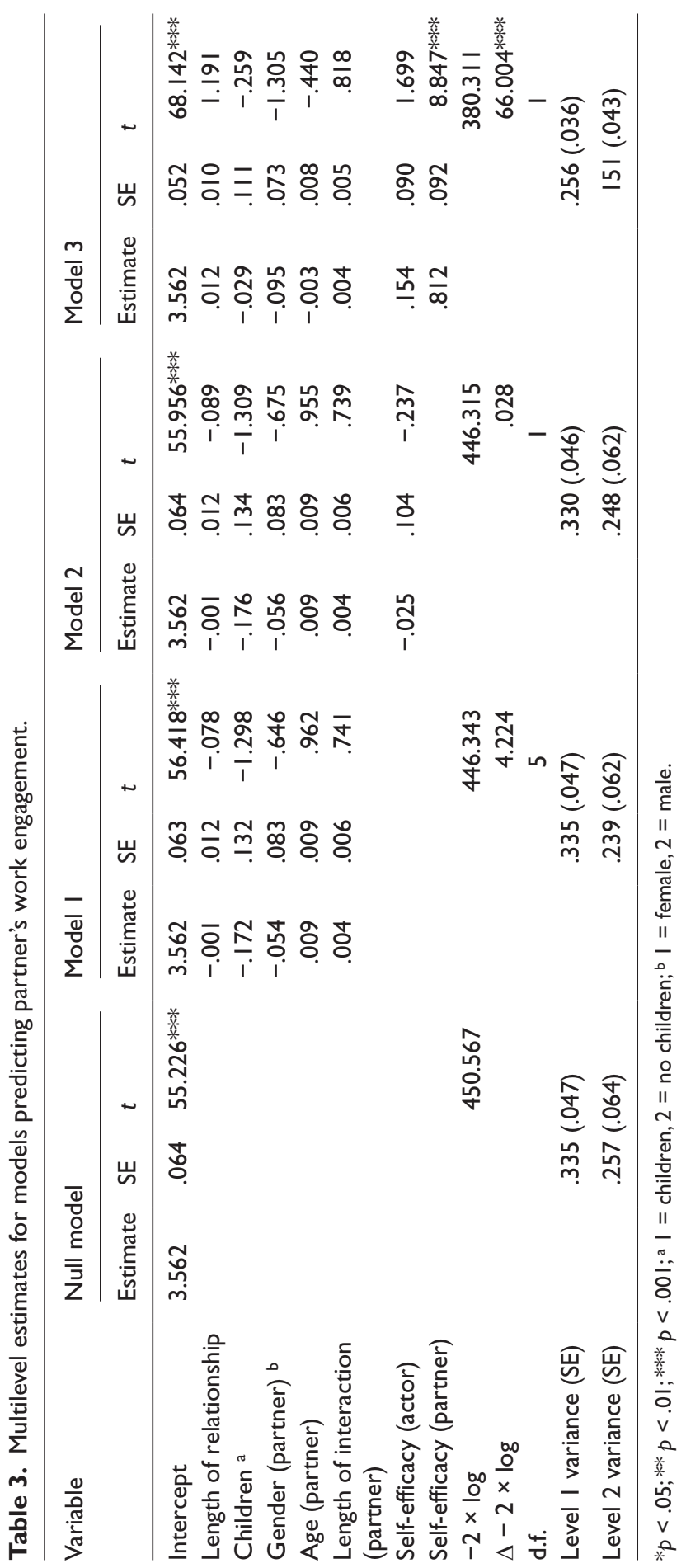


than the intercept-only model $(\Delta-2 \times \log =13.672$, d.f. $=5, p<.05)$. The partner's age was the only significant predictor variable in this model with partner's age being positively related to partner's job-related self-efficacy. Model 2 that included the actor's job-related self-efficacy as predictor variable showed a significant improvement over Model $1(\Delta-2 \times \log =4.734$, d.f. $=1, p<.05)$. Also, the unstandardized estimate of the actor's job-related self-efficacy was highly significant. To conclude, as hypothesized, the actor's job-related self-efficacy predicted the partner's jobrelated self-efficacy. Thus, data supported Hypothesis 1.

Mechanisms linking the crossover of job-related self-efficacy (Hypothesis 2). To test Hypotheses $2 \mathrm{a}$ and $2 \mathrm{~b}$, we first tested whether both hypothesized mediator variables (i.e. partner's perceived vicarious experience and verbal persuasion) were predicted by the actor's jobrelated self-efficacy. As expected, the actor's job-related self-efficacy positively predicted both the partner's perceived vicarious experience $(\gamma=.456, \mathrm{SE}=.071, t=6.442, p<.001)$ and the partner's perceived verbal persuasion $(\gamma=.236, \mathrm{SE}=.088, t=2.678, p<.01)$ (after controlling for the same control variables as in Hypothesis 1). In a second step, we tested whether both mediator variables significantly predicted the partner's job-related self-efficacy. We thereby compared the same three models as we did when testing Hypothesis 1 . This time, however, in a fourth step, we included vicarious experience and verbal persuasion as mediator variables (Model 3). The results are again depicted in Table 2. Adding both mediator variables in Model 3 resulted in a highly significant improvement of model fit over Model $2(\Delta-2 \times \log =46.918$, d.f. $=2, p<.001)$. Furthermore, the partner's perceived vicarious experience and verbal persuasion were significant predictors for the partner's job-related self-efficacy (see Table 2). To test the indirect effects of the actor's job-related self-efficacy on the partner's job-related self-efficacy via the partner's vicarious experience and verbal persuasion, we bootstrapped both indirect effects simultaneously with a single-level bootstrapping approach as recommended by Preacher and Hayes (2008) for multiple mediator models. The indirect effect from the actor's jobrelated self-efficacy on the partner's job-related self-efficacy through vicarious experience was $.090,95$ per cent CI $[.021, .184]$. The indirect effect from the actor's job-related self-efficacy on the partner's job-related self-efficacy via verbal persuasion was .083, 95 per cent CI [.035, .162]. Thus, results supported Hypotheses $2 \mathrm{a}$ and $2 \mathrm{~b}$.

Work-related consequences of the crossover of job-related self-efficacy (Hypothesis 3). Hypothesis 3 postulated that the actor's job-related self-efficacy indirectly relates to the partner's work engagement via the partner's job-related self-efficacy. However, we did not hypothesize a direct effect of the actor's job-related self-efficacy on the partner's work engagement. According to Mathieu and Taylor (2006), this is a case of an indirect effect. The test of Hypothesis 1 had already shown that the actor's job-related self-efficacy positively related to the partner's job-related self-efficacy. To test whether the partner's jobrelated self-efficacy was positively related to his or her work engagement we again applied hierarchical linear modeling (see Table 3). Our analyses revealed that Model 1 (including the control variables) showed no better model fit than the intercept-only model $(\Delta-2 \times \log =4.224$, d.f. $=5$, ns $)$. None of the control variables significantly predicted the partner's work engagement. Furthermore, including the actor's job-related 
self-efficacy in Model 2 did not result in a better model fit as well $(\Delta-2 \times \log =.028$, d.f. $=1$, ns). Thus, as expected, the actor's job-related self-efficacy did not directly predict the partner's work engagement. However, including the partner's job-related selfefficacy in Model 3 resulted in a significant improvement over Model $2(\Delta-2 \times \log =$ 66.004, d.f. $=1, p<.001$ ) with the partner's job-related self-efficacy being a significant predictor of his or her work engagement. To test the indirect effect of the actor's jobrelated self-efficacy on the partner's work engagement via the partner's job-related selfefficacy, we again bootstrapped the indirect effect of the actor's job-related self-efficacy on the partner's work engagement through the partner's job-related self-efficacy. We hereby used the approach to test ordinary single-level mediation as described by Preacher and Hayes (2004). Results revealed that the hypothesized indirect effect was .195, 95 per cent CI [.060, .325]. Thus, data supported Hypothesis 3.

\section{Additional analyses}

Ruling out alternative explanations:Assortative mating. To rule out the alternative explanation referring to the partners' initial similarity we tested whether the couples' educational similarity as well as their initial general similarity moderated the crossover effect. We again applied hierarchical linear modeling comparing four nested models: The null model, Model 1 (including the same control variables as in the previous analyses), Model 2 (including the main effects, i.e. general similarity, educational similarity, and the actor's job-related self-efficacy), and Model 3 (including the interaction terms). Table 4 shows the results. Analyses showed that neither the couples' general nor their educational similarity were significant moderators influencing the strength or direction of the relation between both partners' job-related self-efficacy. ${ }^{1}$ Thus, crossover of job-related self-efficacy seems to occur irrespective of the couple's initial similarity.

Testing gender as a moderator. One might argue that gender moderates the strength of crossover effects (Bakker et al., 2011; Demerouti et al., 2005). For example, concerning the crossover of stress and strain, Westman (2001) hypothesized women to be more susceptible to crossover effects than their male partners. However, empirical evidence concerning gender effects within crossover processes is quite inconsistent (Westman, 2001) and therefore hard to hypothesize a priori. Thus, we tested potential moderator effects of gender on the crossover of job-related self-efficacy with an exploratory approach.

In a first step, we tested if gender moderates the overall crossover of job-related selfefficacy. We included - in addition to the main effects of the actor's job-related self-efficacy and the partner's gender - the interaction between the actor's job-related self-efficacy and partner's gender in the regression equation and compared this model with Model 2 reported in Table 2. We found that for the prediction of the partner's job-related self-efficacy, including the interaction term in the equation did not result in a significant improvement over Model $2(\Delta-2 \times \log =.059$, d.f. $=1$, ns $)$. Also, the interaction term was no significant predictor of the partner's job-related self-efficacy. This means that the overall crossover of job-related self-efficacy does not differ between men and women.

Furthermore, we tested whether the prediction of our hypothesized mediators, i.e. partner's perceived verbal persuasion and vicarious experience, was moderated by 


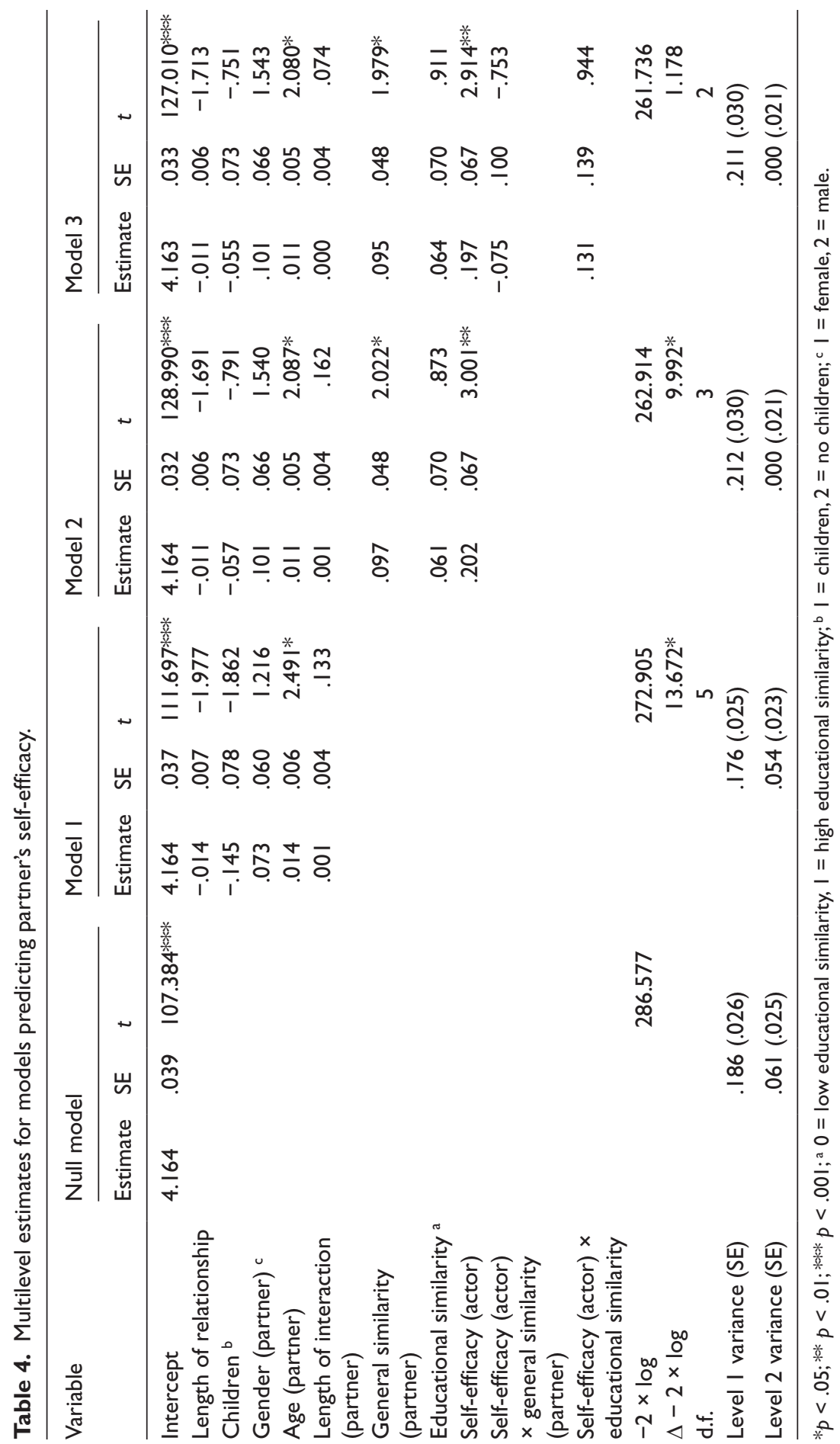


gender. We included the interaction term between the actor's job-related self-efficacy and the partner's gender in the equation and compared this model with the equation in which only the main effects of the actor's job-related self-efficacy and the partner's gender were included. Concerning verbal persuasion, including this interaction term neither resulted in a significant improvement of model fit $(\Delta-2 \times \log =.75$, d.f. $=1$, ns $)$ nor was the interaction term a significant predictor of the partner's perceived verbal persuasion. Thus, concerning the prediction of partner's perceived verbal persuasion, there are no gender differences.

By contrast, concerning vicarious experience, the inclusion of the interaction term between the actor's job-related self-efficacy and the partner's gender resulted in a better model fit $(\Delta-2 \times \log =4.487$, d.f. $=1, p<.05)$. Also, the interaction term significantly predicted the partner's perceived vicarious experience. This moderation is illustrated in Figure 2 and suggests a steeper slope for women than for men.

As suggested by Preacher et al. (2006), we probed the simple slopes. Simple slopes were significant for both male and female partners (female partners: estimate $=.61, \mathrm{SE}$ $=.10, z=6.10, p<.001$; male partners: estimate $=.31, \mathrm{SE}=.10, z=3.26, p<.01)$. Thus, despite significant moderation, the actor's job-related self-efficacy predicted the partner's perceived vicarious experience, both for male and female partners. This finding suggests that although men seem to be a stronger role model for their female partners than vice versa, the relation between the actor's job-related self-efficacy and the partner's vicarious experience is significant for both male and female partners.

To conclude, the overall crossover of job-related self-efficacy occurs for both men and women. Also, the mechanisms underlying this crossover process are similar for men

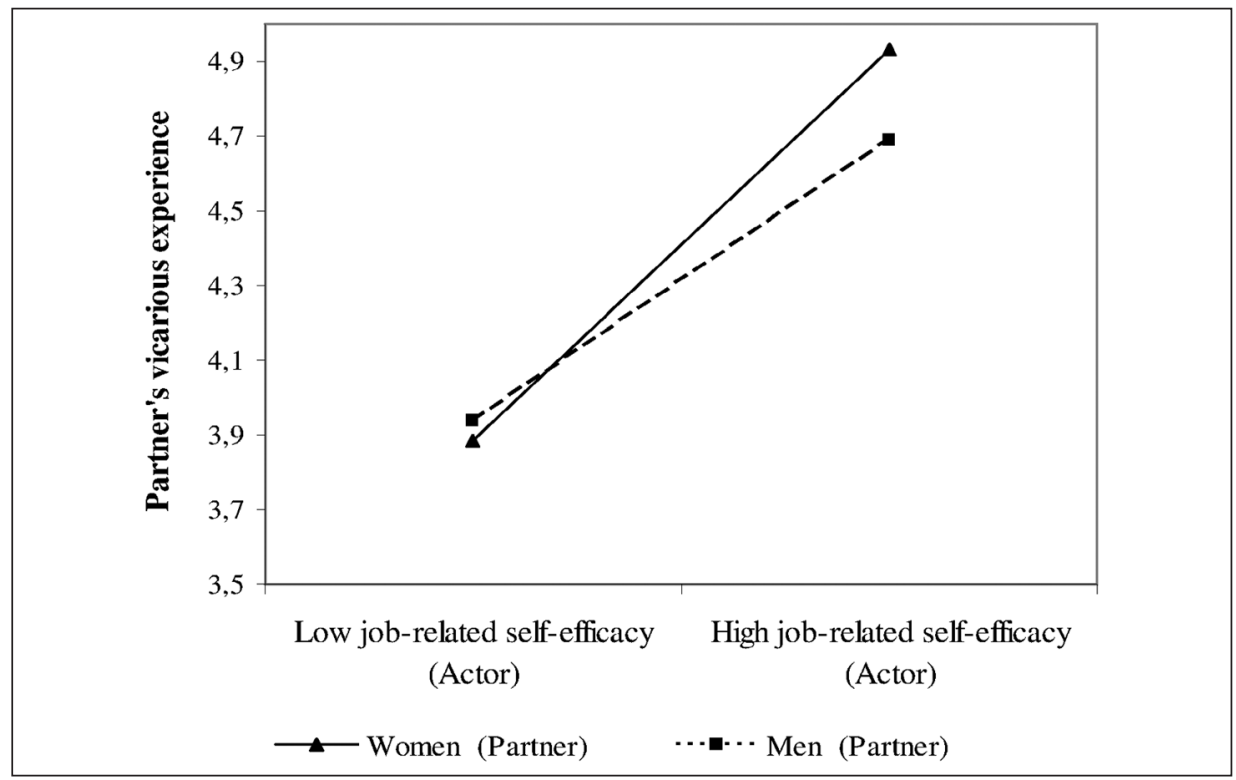

Figure 2. Interaction effect of the actor's job-related self-efficacy and the partner's gender on the partner's vicarious experience. 
and women. Although women seem to be more prone to behavioral modeling concerning job-related self-efficacy by their male partners than vice versa, men's perceived vicarious experience was significantly predicted by their female spouses as well. For verbal persuasion there was no moderating gender effect at all.

\section{Discussion}

The aim of this study was to examine the crossover of job-related self-efficacy, the mechanisms linking the crossover process, and its work-related consequences. We showed that the actor's job-related self-efficacy crosses over to the partner's job-related selfefficacy and that this crossover effect is mediated by the partner's perceived vicarious experience and verbal persuasion. In a further step, we showed that the crossover of jobrelated self-efficacy indirectly relates to the partner's perceived work engagement.

\section{Research contributions}

In our study, we wanted to contribute to existing research in two central ways. First, we wanted to add to research on sources of employees' job-related self-efficacy. Until now, research on sources of employees' job-related self-efficacy has merely focused on workrelated antecedents (Eden et al., 2000; McNatt and Judge, 2008). However, focusing exclusively on these work-related antecedents - though offering interesting results - had shown that a large portion of the variance in a person's job-related self-efficacy remains unaccounted for (e.g. McNatt and Judge, 2004). Thus, because a person's work and private lives are mutually intertwined (Eby et al., 2005; Voydanoff, 2002), we proposed that non-work-related sources might additionally predict a person's job-related self-efficacy. Our finding of a crossover of job-related self-efficacy between working partners supports this proposition. Of course, this crossover process can also only partly explain a person's job-related self-efficacy. Nevertheless, our results highlight that in order to gain a better understanding of how a person's job-related self-efficacy develops, sources outside the focal person's immediate work environment - and especially this person's working partner - should be taken into account. Moreover, we found that the crossover of job-related self-efficacy is mediated by two central sources of self-efficacy as proposed by Bandura (1997): the partner's perceived vicarious experience and verbal persuasion. Although vicarious experience and verbal persuasion have already been taken into account as work-related antecedents of employees' job-related self-efficacy (Eden and Kinnar, 1991; Mellor et al., 2006; Prussia and Kinicki, 1996), our results suggest that similar processes occur between partners in dual-earner relationships. Thus, a person's partner seems to be an additional reference point for his or her job-related self-efficacy and therefore, most likely, by interacting and talking to the partner, a person's own jobrelated self-efficacy can be affected.

Second, by investigating the crossover of job-related self-efficacy within working couples we wanted to extend research on crossover processes (Westman, 2001). Until now, in line with a conflict perspective on the interplay between a person's working and private lives (Hammer et al., 1997), crossover research has mostly studied the transmission of negative psychological states within dual-earner couples (Bakker et al., 2009). 
Going beyond this negative crossover perspective, in our study, we showed that jobrelated self-efficacy - as a central positive work-related self-evaluation (Abele and Spurk, 2009; Stajkovic and Luthans, 1998) - can also cross over between partners. This finding corresponds to the idea that the interplay between a person's working and private lives can also be enriching (Greenhaus and Powell, 2006). Additionally, this notion is underpinned by our finding that the crossover of job-related self-efficacy was in turn related to the other partner's work engagement. Thus, one's partner can not only positively affect one's job-related self-efficacy through crossover processes, but this transmission in turn is related to one's work engagement.

In addition to these research contributions, our study sheds more light on the role of one's partner for working life. Previous research has mainly looked at the benefits of one's partner with respect to affective and well-being outcomes, resulting, for instance, from emotional social support (Granrose et al., 1992) or from interpersonal capitalization when talking to one's partner about positive events that happened at work (Ilies et al., 2011). Our study suggests that one's partner has also the potential to boost one's jobrelated self-efficacy, thereby possibly affecting cognitive-motivational processes at work.

To rule out alternative explanations, we additionally conducted moderation analyses. Hereby, we showed that the crossover of job-related self-efficacy accounts for all couples in our whole sample irrespective of their initial general similarity or educational similarity. This finding is particularly interesting as research on 'assortative mating' (Gonzaga et al., 2007; Tambs and Moum, 1992) has shown that partners' similarity with respect to various attributes such as behavior or personality can - at least to some extent - stem from the initial selection of similar partners. Although we cannot completely rule out an explanation referring to 'assortative mating', the moderator analyses suggest that our core findings cannot be accounted for by the partners' initial similarity on some core features.

Furthermore, to test for possible gender asymmetries, we examined whether the partner's gender was a moderator in the crossover process. Overall, the results of these additional analyses showed similar crossover patterns for men and women. We found no moderation effect of partner's gender for the overall crossover of job-related self-efficacy. Moreover, verbal persuasion and vicarious experiences mediated the crossover of job-related self-efficacy for both men and women. However, although significant for both sexes, women's selfefficacy experiences seem to be more strongly modeled by their male partners than vice versa. Although previous research on gender effects in crossover processes has brought quite inconsistent results, this finding goes in line with Westman's (2001) proposition of stronger crossover effects of strain on female partners than vice versa.

\section{Research limitations}

Our study has some limitations. First, the study was cross-sectional, which impairs causal interpretations of our findings. However, by performing additional similarity analyses, we tried to rule out the most obvious alternative explanation - the similarity of the partners' job-related self-efficacy owing to initial similarity in educational level and other core variables. Our moderation analyses showed that the crossover effects stayed significant when taking the similarity measures into account. However, although grounded in Bandura's self-efficacy research (1997), other processes might account for 
our study results. For example, work engagement also has been found to cross over between partners (Bakker and Demerouti, 2009). Therefore, alternatively or additionally, the positive association between both partners' job-related self-efficacy might also be owing to a crossover of work engagement. Thus, future research should try to replicate our findings using methodological approaches that allow stronger causal conclusions.

A second limitation of our study is that it relied exclusively on self-reports. Using self-report data increases the risk of common method bias (Podsakoff et al., 2003). We tried to reduce common method variance by letting both partners rate their job-related self-efficacy independently. Furthermore, multilevel confirmatory factor analyses revealed that job-related self-efficacy, vicarious experience, verbal persuasion and work engagement constituted empirically distinct constructs. Future research, however, should validate our findings by using data from other sources such as work engagement ratings from co-workers.

\section{Practical implications and future research}

Our study showed that job-related self-efficacy unfolds its impact beyond the work context. Thus, high job-related self-efficacy is not only beneficial for a number of job-related outcomes (Abele and Spurk, 2009; Stajkovic and Luthans, 1998); it also seems to be brought home, thereby affecting one's partner via crossover processes. This finding has practical implications for dual-earner couples and the organizations they work in, and reveals important questions for future research.

On the one hand, as to our study's practical implications, we want to highlight two central implications. First, concerning partners in dual-earner relationships themselves, when realizing that one's partner currently has a hard time at work, our results suggest that one can support this partner's self-efficacy beliefs actively, for example, through verbal encouragement. This means that by showing faith in one's partner's capabilities one partner seems to be able to foster the other partner's job-related self-efficacy. Also, apparently, speaking about one's own accomplishments and one's ways of dealing with difficulties can additionally model the partner's job-related self-efficacy beliefs.

Second, the positive relation between job-related self-efficacy and work engagement found in our study once again underlines that it is central to increasing employees' jobrelated self-efficacy. Thereby, our results suggest that fostering employees' job-related self-efficacy at work might even have salutary effects on their partners at home. Fostering employees' job-related self-efficacy might then ideally even lead to an inter-individual upward spiral. Specifically, supporting employees' job-related self-efficacy at work (for example, through a leadership style that conveys high performance expectations, a supportive climate, and internal attributions of employees' successes; Eden, 1992) might positively affect their partners via crossover processes that can in turn positively affect the partners' work engagement. Experiencing higher work engagement might then again increase the partners' job-related self-efficacy (Xanthopoulou et al., 2009a) and can then again be transmitted to the employees themselves.

On the other hand, because, to our knowledge, our study was the first to investigate a crossover of job-related self-efficacy, it raises interesting questions for future research. First, our results suggest that there can also be a downside to a crossover of job-related 
self-efficacy, as low job-related self-efficacy might also cross over between partners. Future research should therefore try to identify moderators that influence the strength of the crossover of job-related self-efficacy. Ideally, this could help employees and organizations to facilitate the crossover of high job-related self-efficacy and to impede the crossover of low job-related self-efficacy. For example, Boundary Theory (Ashforth et al., 2000) postulates inter-individual differences concerning how much people tend to integrate and separate their work and private lives. Thereby, people who integrate both life domains could be more likely to carry home work-related experiences from work into their private lives (e.g. Ilies et al., 2009). Applied to the cross over of job-related self-efficacy, if a person tends to separate his or her life domains, he or she possibly will speak less with his or her partner about work-related issues and therefore a cross over of job-related self-efficacy might be less likely to occur. This moderating role of boundary strategies also would have important implications for organizations. For example, they could actively support the crossover of job-related self-efficacy by offering integration supplies like flexible working hours (Kreiner, 2006).

Second, after our study has demonstrated that sources outside one's immediate work context (i.e. one's partner's job-related self-efficacy) are related to a person's job-related self-efficacy, future research might want to examine work-related and non-work sources of job-related self-efficacy in one study. Therefore, the relative importance of the work vs non-work sources could be determined, and it could be tested if these two sources interact (e.g. amplifying vs compensating for each other).

\section{Conclusion}

To conclude, the results of our study suggest that a person's non-work social environment and particularly his or her working partner can be an additional source of job-related selfefficacy. This supports the importance of the interplay between work and family (Grzywacz and Marks, 2000) and encourages research and practice to broaden its view on crossover processes as well as on the benefits of careers within dual-earner relationships.

\section{Appendix}

Vicarious Experience Scale (adapted from Lent et al., 1991):

1. At work, my partner is able to achieve most of the goals that he/she has set for him-/ herself.

2. When facing difficult tasks at work, my partner is certain that he/she will accomplish them.

3. At work, my partner can obtain outcomes that are important to him/her.

4. My partner believes that at work he/she can succeed at most any endeavor to which he/she sets his/her mind.

5. At work, my partner is able to overcome many challenges successfully.

6. My partner is confident that he/she can perform effectively on many different workrelated tasks.

7. Compared with other people, my partner can do most tasks very well at work.

8. Even when things are tough at work, my partner can perform quite well. 
Verbal Persuasion Scale (adapted from Lent et al., 1991):

1. My partner encourages me that I am able to achieve most of the goals that I have set for myself at work.

2. When facing difficult tasks at work, my partner tells me that I will accomplish them.

3. My partner encourages me that I can obtain outcomes that are important to me at work.

4. My partner believes that at work, I can succeed at most any endeavor to which I set my mind.

5. My partner tells me that I am able to overcome many challenges at work successfully.

6. My partner encourages me to be confident that I can perform effectively on many different work-related tasks.

7. My partner believes that, compared with other people, I can do most tasks very well at work.

8. My partner encourages me that, even when things are tough at work, I can perform quite well.

\section{Funding}

This article is part of Angela Neff's doctoral dissertation and was supported by a grant from the University of Konstanz to Sabine Sonnentag (No 12/00).

\section{Notes}

1. The moderator terms also stayed non-significant when entered separately into the equation.

\section{References}

Abele AE and Spurk D (2009) The longitudinal impact of self-efficacy and career goals on objective and subjective career success. Journal of Vocational Behavior 74(1): 53-62.

Aryee S, Luk V, Leung A and Lo S (1999) Role stressors, interrole conflict, and well-being: The moderating influence of spousal support and coping behaviors among employed parents in Hong Kong. Journal of Vocational Behavior 54(2): 259-278.

Ashforth BE, Kreiner GE and Fugate M (2000) All in a day's work: Boundaries and micro role transitions. Academy of Management Review 25(3): 472-491.

Bakker AB (2005) Flow among music teachers and their students: The crossover of peak experiences. Journal of Vocational Behavior 66(1): 26-44.

Bakker AB and Bal PM (2010) Weekly work engagement and performance: A study among starting teachers. Journal of Occupational and Organizational Psychology 83(1): 189-206.

Bakker AB and Demerouti E (2009) The crossover of work engagement between working couples: A closer look at the role of empathy. Journal of Managerial Psychology 24(3): 220-236.

Bakker AB, Demerouti E and Verbeke W (2004) Using the job demands-resources model to predict burnout and performance. Human Resource Management 43(1): 83-104.

Bakker AB, Demerouti E and Dollard MF (2008) How job demands affect partners' experience of exhaustion: Integrating work-family conflict and crossover theory. Journal of Applied Psychology 93(4): 901-911.

Bakker AB, Westman M and van Emmerik IJH (2009) Advancements in crossover theory. Journal of Managerial Psychology 24(3): 206-219. 
Bakker AB, Shimazu A, Demerouti E, Shimada K and Kawakami N (2011) Crossover of work engagement among Japanese couples: Perspective taking by both partners. Journal of Occupational Health Psychology 16(1): 112-125.

Bandura A (1977a) Self-efficacy: Toward a unifying theory of behavioral change. Psychological Review 84(2): 191-215.

Bandura A (1977b) Social Learning Theory. Oxford, UK: Prentice-Hall.

Bandura A (1997) Self-efficacy: The Exercise of Control. New York: W. H. Freeman and Company.

Bryk AS and Raudenbush SW (1992) Hierarchical Linear Models: Applications and Data Analysis Methods. Thousand Oaks, CA: SAGE.

Chen G, Gully SM and Eden D (2001) Validation of a new general self-efficacy scale. Organizational Research Methods 4(1): 62-83.

Demerouti E, Bakker AB and Schaufeli WB (2005) Spillover and crossover of exhaustion and life satisfaction among dual-earner parents. Journal of Vocational Behavior 67(2): 266-289.

Eby LT, Casper WJ, Lockwood A, Bordeaux C and Brinley A (2005) Work and family research in IO/OB: Content analysis and review of the literature (1980-2002). Journal of Vocational Behavior 66(1): 124-197.

Eden D (1992) Leadership and expectations: Pygmalion effects and other self-fulfilling prophecies in organizations. The Leadership Quarterly 3(4): 271-305.

Eden D, Kinnar J (1991) Modeling Galatea: Boosting self-efficacy to increase volunteering. Journal of Applied Psychology 76(6): 770-780.

Eden D, Geller D, Gewirtz A, et al. (2000) Implanting Pygmalion leadership style through workshop training: Seven field experiments. The Leadership Quarterly 11(2): 171-210.

Gonzaga GC, Campos B and Bradbury T (2007) Similarity, convergence, and relationship satisfaction in dating and married couples. Journal of Personality and Social Psychology 93(1): $34-48$.

Granrose CS, Parasuraman S and Greenhaus JH (1992) A proposed model of support provided by two-earner couples. Human Relations 45(12): 1367-1393.

Greenhaus JH and Powell GN (2006) When work and family are allies: A theory of work-family enrichment. Academy of Management Review 31(1): 72-92.

Grzywacz JG and Marks NF (2000) Reconceptualizing the work-family interface: An ecological perspective on the correlates of positive and negative spillover between work and family. Journal of Occupational Health Psychology 5(1): 111-126.

Hammer LB, Allen E and Grigsby TD (1997) Work-family conflict in dual-earner couples: Within-individual and crossover effects of work and family. Journal of Vocational Behavior 50(2): 185-203.

Ilies R, Keeney J and Scott BA (2011) Work-family interpersonal capitalization: Sharing positive work events at home. Organizational Behavior and Human Decision Processes 114(2): 115-126.

Ilies R, Schwind KM, Wagner DT, et al. (2007) When can employees have a family life? The effects of daily workload and affect on work-family conflict and social behaviors at home. Journal of Applied Psychology 92(5): 1368-1379.

Ilies R, Wilson KS and Wagner DT (2009) The spillover of daily job satisfaction onto employees' family lives: The facilitating role of work-family integration. Academy of Management Journal 52(1): 87-102.

Kenny DA, Kashy DA and Cook WL (2006) Dyadic Data Analysis. New York, NY: Guilford Press.

Knabb JJ, Vogt RG, Gibbel MR and Brickley DJ (2012) An empirical investigation of the relationship between clinical personality patterns and marital functioning. Couple and Family Psychology: Research and Practice 1(1): 66-77. 
Kreiner GE (2006) Consequences of work-home segmentation or integration: A person-environment fit perspective. Journal of Organizational Behavior 27(4): 485-507.

Lent RW, Lopez FG and Bieschke KJ (1991) Mathematics self-efficacy: Sources and relation to science-based career choice. Journal of Counseling Psychology 38(4): 424-430.

McNatt DB and Judge TA (2004) Boundary conditions of the galatea effect: A field experiment and constructive replication. Academy of Management Journal 47(4): 550-565.

McNatt DB and Judge TA (2008) Self-efficacy intervention, job attitudes, and turnover: A field experiment with employees in role transition. Human Relations 61(6): 783-810.

Mathieu JE and Taylor SR (2006) Clarifying conditions and decision points for mediational type inferences in organizational behavior. Journal of Organizational Behavior 27(8): 1031-1056.

Mellor S, Barclay LA, Bulger CA and Kath LM (2006) Augmenting the effect of verbal persuasion on self-efficacy to serve as a steward: Gender similarity in a union environment. Journal of Occupational and Organizational Psychology 79(1): 121-129.

Neumann R and Strack F (2000) 'Mood contagion': The automatic transfer of mood between persons. Journal of Personality and Social Psychology 79(2): 211-223.

Pinkus RT, Lockwood P, Schimmack U and Fournier MA (2008) For better and for worse: Everyday social comparisons between romantic partners. Journal of Personality and Social Psychology 95(5): 1180-1201.

Podsakoff PM, MacKenzie SB, Lee J-Y and Podsakoff NP (2003) Common method biases in behavioral research: A critical review of the literature and recommended remedies. Journal of Applied Psychology 88(5): 879-903.

Preacher KJ, Curran PJ and Bauer DJ (2006) Computational tools for probing interactions in multiple linear regression, multilevel modeling, and latent curve analysis. Journal of Educational and Behavioral Statistics 31(4): 437-448.

Preacher KJ and Hayes AF (2004) SPSS and SAS procedures for estimating indirect effects in simple mediation models. Behavior Research Methods, Instruments, \& Computers 36(4): $717-731$.

Preacher KJ and Hayes AF (2008) Asymptotic and resampling strategies for assesssing and comparing indirect effects in multiple mediator models. Behavior Research Methods 40(3): 879891.

Prussia GE and Kinicki AJ (1996) A motivational investigation of group effectiveness using social-cognitive theory. Journal of Applied Psychology 81(2): 187-198.

Raudenbush SW, Bryk AS, Cheong YF and Congdon RT (2004) HLM 6: Hierarchical Linear and Nonlinear Modeling. Lincolnwood, IL: Scientific Software International.

Salanova M, Agut S and Peiró JM (2005) Linking organizational resources and work engagement to employee performance and customer loyalty: The mediation of service climate. Journal of Applied Psychology 90(6): 1217-1227.

Schaufeli WB and Bakker AB (2004) Job demands, job resources, and their relationship with burnout and engagement: A multi-sample study. Journal of Organizational Behavior 25(3): 293-315.

Schaufeli WB, Bakker AB and Salanova M (2006) The measurement of work engagement with a short questionnaire: A cross-national study. Educational and Psychological Measurement 66(4): 701-716.

Schmitt N (2008) The interaction of neuroticism and gender and its impact on self-efficacy and performance. Human Performance 21(1): 49-61.

Seiger CP and Wiese BS (2009) Social support from work and family domains as an antecedent or moderator of work-family conflicts? Journal of Vocational Behavior 75(1): 26-37.

Selenko E, Batinic B and Paul K (2011) Does latent deprivation lead to psychological distress? Investigating Jahoda's model in a four-wave study. Journal of Occupational and Organizational Psychology 84(4): 723-740. 
Song Z, Foo M-D and Uy MA (2008) Mood spillover and crossover among dual-earner couples: A cell phone event sampling study. Journal of Applied Psychology 93(2): 443-452.

Song Z, Foo M-D, Uy MA and Sun S (2010) Unraveling the daily stress crossover between unemployed individuals and their employed spouses. Journal of Applied Psychology 96(1): $151-168$.

Stajkovic AD and Luthans F (1998) Self-efficacy and work-related performance: A meta-analysis. Psychological Bulletin 124(2): 240-261.

Tambs K and Moum T (1992) No large convergence during marriage for health, lifestyle, and personality in a large sample of Norwegian spouses. Journal of Marriage \& the Family 54(4): 957-971.

Voydanoff P (2002) Linkages between the work-family interface and work, family, and individual outcomes: An integrative model. Journal of Family Issues 23(1): 138-164.

Wang P, Lawler JJ and Shi K (2010) Work-family conflict, self-efficacy, job satisfaction, and gender: Evidences from Asia. Journal of Leadership \& Organizational Studies 17(3): 298-308.

Westman M (2001) Stress and strain crossover. Human Relations 54(6): 717-752.

Xanthopoulou D, Bakker AB, Heuven E, Demerouti E and Schaufeli WB (2008) Working in the sky: A diary study on work engagement among flight attendants. Journal of Occupational Health Psychology 13(4): 345-356.

Xanthopoulou D, Bakker AB, Demerouti E and Schaufeli WB (2009a) Reciprocal relationships between job resources, personal resources, and work engagement. Journal of Vocational Behavior 74(3): 235-244.

Xanthopoulou D, Bakker AB, Demerouti E and Schaufeli WB (2009b) Work engagement and financial returns: A diary study on the role of job and personal resources. Journal of Occupational and Organizational Psychology 82(1): 183-200.

Angela Neff finished her doctoral dissertation as a research assistant at the Work and Organizational Psychology unit at the University of Konstanz, Germany, in 2012. Her research focuses on the interplay between employees' work and private lives and the crossover of job-related self-evaluations within working couples. [Email: angela.neff@uni-konstanz.de]

Cornelia Niessen is a full professor in Work and Organizational Psychology at the FriedrichAlexander University of Erlangen-Nürnberg, Germany. Dr Niessen's research interests are in the areas of adaptive performance, vitality, proactive behavior, and aging at work. She has published in journals such as Journal of Organizational Behavior, Journal of Occupational Health Psychology, Journal of Occupational and Organizational Psychology, and Leadership Quarterly. [Email: cornelia.niessen@psy.phil.uni-erlangen.de]

Sabine Sonnentag is a full professor of Work and Organizational Psychology at the University of Mannheim, Germany. Her research addresses the question of how individuals can achieve sustainable high performance at work and remain healthy at the same time. She studies recovery from job stress, proactive work behavior, learning and self-regulation in the job context. She publishes in journals such as Journal of Applied Psychology, Journal of Organizational Behavior, Journal of Occupational Health Psychology, and Personnel Psychology. She has been the editor-in-chief of Applied Psychology: An International Review and currently serves on the editorial boards of several scholarly journals. [Email: sonnentag@uni-mannheim.de]

Dana Unger is a research assistant in the Work and Organizational Psychology unit at the University of Mannheim, Germany. She is interested in how self-regulatory processes affect the interplay of work demands and experiences within romantic relationships at the work-life interface. [Email: dana.unger@uni-mannheim.de] 